\title{
ANALISIS STRUKTUR KALIMAT PASIF BAHASA INGGRIS DAN BAHASA INDONESIA MELALUI CONTRASTIVE RECOGNITION
}

\author{
Rifa Suci Wulandari, Siti Zulaihah, Hestri Hurustyanti \\ STKIP PGRI Ponorogo \\ meilanty_06@yahoo.co.id
}

\begin{abstract}
Abstrak
Tujuan penelitian ini adalah untuk mengetahui struktur kalimat pasif dalam Bahasa Inggris, kalimat pasif dalam Bahasa Indonesia dan perbandingan kalimat pasif dalam Bahasa Inggris dan Bahasa Indonesia. Peneliti menggunakan jenis penelitian kepustakaan (library research), Analisis yang dipakai dalam penelitian ini adalah analisis isi (content analysis). Hasil Analisis menunjukkan bahwa padanan dan perbandingan kalimat pasif dalam Bahasa Inggris dan Bahasa Indonesia dapat dilihat secara struktural maupun secara pragmatis. Secara struktural terdapat persamaan kalimat pasif dalam Bahasa Inggris dan Bahasa Indonesia yaitu subjeknya yang dikenai tindakan dan objeknya sebagai pelaku yang ditandai dengan kata by atau kata oleh dalam Bahasa Indonesia, sedangkan perbedaannya adalah dalam Bahasa Inggris terdapat perbedaan waktu pengucapan. Dalam Bahasa Indonesia, kalimat pasif diucapkan sama meskipun diucapkan sekarang (present), masa depan (future), ataupun masa lalu (past). Dalam Bahasa Inggris, kata kerja yang digunakan dalam masing-masing tenses berbeda karena perbedaan waktu, sedangkan dalam Bahasa Indonesia tidak ada perbedaan penggunaan kata kerja. Secara pragmatis, makna yang terkandung di dalam kalimat pasif Bahasa Inggris sama dengan makna yang terkandung dalam Bahasa Indonesia, yaitu sama-sama menyatakan objek sebagai pelaku dan subjek sebagai penerima tindakan. Perbedaannya terletak pada makna adversatif dan ketidaksengajaan. Dalam Bahasa Inggris tidak terdapat kalimat pasif yang bermakna ketidaksengajaan.
\end{abstract}

Kata kunci: analisis kontrastif, struktur, kalimat pasif

\begin{abstract}
The aims of this research are to know the passive structure of English and Indonesian sentence, and the comparison of passive sentence in English and Indonesian. The researcher used library research type. This research analysis was content analysis. The results showed that the equivalent and comparison of English and Indonesian passive sentence can be seen structurally and pragmatically. Structurally, there is similarity of English and Indonesian passive sentence, that is the subject receives action and the object is the actor indicated by the use of "by" or "oleh" in Indonesian. The difference is in the time of utterancing. In Indonesian, passive sentence is uttered the same way in all time (present, future, and past). In English, the verbs used differently based on tenses, while in Indonesian there is no difference usage of verbs. Pragmatically, the meaning of English and Indonesian passive sentence is the same, that is stating object as actor and subject as action receiver.The difference is in adversative and unintended meaning. There is no unintended meaning in English passive sentence.
\end{abstract}

Key words: contrastive analysis, structure, passive sentence

\section{PENDAHULUAN}

Di Indonesia terdapat berbagai macam bahasa, yang terdiri atas bahasa daerah, bahasa Indonesia, dan bahasa Inggris yang berperan sebagai bahasa asing, sedangkan kedudukan bahasa daerah di Indonesia ialah sebagai bahasa ibu (mother tongue) yang digunakan dalam kehidupan sehari-hari dalam bermasyarakat. Bahasa Indonesia digunakan pada saat situasi formal pada 
saat di lingkungan pemerintahan atau sekolah, sedangkan bahasa Inggris merupakan bahasa asing yang dimasukkan dalam mata pelajaran di tingkat sekolah dasar sampai pada jenjang perguruan tinggi. Hal itu berbeda dengan negara tetangga, seperti Singapura yang lebih maju dalam penguasaan berbahasa Inggrisnya karena bahasa Inggris menjadi bahasa kedua di Singapura sehingga mereka lebih terbiasa dan fasih menggunakan bahasa tersebut (Richards, 1974).

Pengajaran Bahasa Inggris di Indonesia di tingkat pendidikan dasar dan menengah lebih banyak ditekankan pada kemampuan menghafal dibandingkan dengan memahami. Hal tersebut dirasakan kurang mendukung dalam mempersiapkan seseorang untuk dapat menggunakan bahasa Inggris dalam komunikasi. Peserta didik kurang mampu memberikan penjelasan atas pemilihan kata, tenses/bentuk waktu dan konstruksi kalimat yang baik dan benar yang sesuai dengan tata bahasa Inggris. Hal ini disebabkan oleh pondasi yang tidak kuat di awal pembelajaran bahasa asing tersebut, khususnya menyangkut semua hal yang berhubungan dengan struktur movement. Struktur movement adalah perpindahan suatu unsur kata di dalam kalimat yang beranjak dari pola awal bentuk aslinya atau deep structure ke dalam bentuk yang sudah diterapkan atau surface structure (Akmajian, 1975:230). Penggunaan struktur sintaksis bahasa Inggris sering terpengaruh bahasa Indonesia. Secara tidak sadar, peserta didik mendapat pengaruh dari bahasa pertama mereka sehingga muncul adanya kesalahan berbahasa terhadap unsur-unsur kata yang dipakainya di dalam kalimat.

Dalam keseharian bila kita perhatikan dengan saksama, sebagai seorang guru atau calon guru yang mengajarkan bahasa Inggris, kita akan menemukan kesalahan-kesalahan yang dibuat oleh peserta didik. Kesalahankesalahan itu dapat kita bedakan dalam dua kategori, yaitu kategori kesalahan dalam bidang keterampilan dan kesalahan dalam bidang linguistik. Kesalahan yang berhubungan dengan keterampilan terjadi pada saat peserta didik menyimak, berbicara, membaca, dan menulis. Sedangkan, kesalahan dalam bidang linguistik meliputi tata bunyi, tata bentuk kata, dan tata kalimat. Guru sering menghadapi kesulitan dalam mengajarkan bahasa kedua (Bahasa Inggris) kepada peserta didiknya. Untuk itu, guru harus mengenal analisis kontrastif. Analisis ini dapat membantu guru bahasa menolong dan sekaligus memperbaiki kesalahan peserta didik. Dengan demikian, peserta didik dapat segera menguasai bahasa sasaran (target language) yang dipelajari.

Analisis kontrastif sebagai suatu pendekatan pengajaran bahasa mengasumsikan bahwa bahasa pertama memengaruhi peserta didik ketika mempelajari bahasa kedua. Analisis kontrastif adalah aktivitas atau kegiatan yang mencoba membandingkan struktur bahasa pertama (B1) dengan struktur bahasa kedua (B2) untuk mengidentifikasi perbedaan-perbedaan di antara kedua bahasa tersebut. Perbedaan-perbedaan antara dua bahasa, yang diperoleh dan dihasilkan melalui Anakon, dapat digunakan sebagai landasan dalam meramalkan atau memprediksi kesulitan - kesulitan atau kendala-kendala belajar berbahasa yang akan dihadapi oleh peserta didik di sekolah., terlebih dalam belajar B2. Hasil perbandingan unsur kebahasaan yang berbeda selanjutnya dianalisis dan dievaluasi untuk membantu guru bahasa meramalkan kesalahan yang kemungkinan dilakukan peserta didik 
dan sekaligus menolong mereka agar segera menguasai bahasa sasaran (B2).

Proses evaluasi merupakan kunci dari sebuah perbaikan metode dan pendekatan untuk meningkatkan prestasi peserta didik. Menurut Brown (2004:4), evaluasi adalah sebuah proses berkelanjutan mencakup banyak domain yang lebih luas. Evaluasi adalah sebuah proses penilaian di mana berdasarkan fungsinya di dalam proses pembelajaran, evaluasi merupakan suatu proses berkelanjutan tentang pengumpulan dan penafsiran informasi untuk menilai keputusan-keputusan yang dibuat dalam merancang suatu sistem pembelajaran. Hal ini menjadi penting untuk membantu guru agar peserta didik memiliki tingkat pemahaman tata bahasa Inggris yang baik dan benar.

Berdasarkan uraian tersebut di atas, maka tujuan penelitian ini adalah untuk mengetahui kalimat pasif dalam Bahasa Inggris, kalimat pasif dalam Bahasa Indonesia dan perbandingan kalimat pasif dalam Bahasa Inggris dan Bahasa Indonesia.

\section{METODE PENELITIAN}

Penelitian ini menggunakan desain penelitian deskriptif kualitatif dengan jenis penelitian kepustakaan (library research. Data primer berupa kalimat-kalimat yang ada dalam buku Understanding and Using English Grammar (Third Edition) karangan Betty Schrampfer Azar dan Tata Bahasa Baku Indonesia karangan Hasan Alwi, dkk. Teknik pengumpulan data yang digunakan dalam penelitian ini adalah teknik simak-catat. Teknik analisis data menggunakan analisis isi (content analysis). Analisis isi menurut Holstin adalah suatu teknik penelitian untuk membuat inferensi yang dilakukan secara objektif dan identifikasi sistematis dari karakteristik pesan (Holstin dalam Iriyanto, 2011:15). Langkah-langkah analisis isi ini mencakup tahapan (1) mengumpulkan data, (2) mereduksi data, (3) pemaparan, (4) pengkodean, (5) menginterpretasi data, dan (6) menarik kesimpulan atas hasil analisis yang berkaitan dengan masalah penelitian. Menurut Miles dan Huberman, analisis data kualitatif mencakup tiga alur kegiatan yang dilakukan secara bersamaan yaitu reduksi data, penyajian data dan penarikan kesimpulan (2007: 16).

\section{HASIL DAN PEMBAHASAN}

Pengajaran Bahasa Inggris tidak lepas dari pengajaran tata bahasa atau grammar. Pengajaran Bahasa Inggris mencakup empat keterampilan bahasa yaitu menyimak (listening), berbicara (speaking), membaca (reading), dan menulis (writing). Pengajaran tata bahasa atau grammar tidak secara eksplisit tercakup dalam keempat keterampilan tersebut. Meskipun demikian, pengajaran grammar menjadi suatu kesatuan dalam pengajaran keempat keterampilan berbahasa. Pada aspek pengajaran Bahasa Inggris, tata bahasa/ grammar merupakan hal yang tidak menarik, baik bagi peserta didik maupun guru. Beberapa guru mencoba mengajarkan grammar menggunakan berbagai teknik tetapi masih saja mengalami kesulitan dalam memahamkan peserta didik.

Salah satu materi grammar yang sulit dipahami oleh peserta didik adalah kalimat pasif. Peserta didik diajarkan kalimat pasif setelah mereka mengerti kalimat aktif. Secara umum dalam Bahasa Inggris, kalimat dibedakan menjadi empat jenis, yaitu (1) kalimat berita, (2) kalimat tanya, (3) kalimat perintah, dan (4) kalimat seru. Di antara 
empat jenis kalimat universal tersebut yang paling banyak dipakai dalam buku-buku dan tulisan-tulisan ilmiah adalah kalimat berita (statement) dalam berbagai bentuknya, seperti: kalimat positif dan negatif, kalimat aktif dan pasif, kalimat langsung dan tidak langsung, kalimat biasa dan pengandaian, kalimat sederhana, majemuk dan kompleks. Semua kalimat itu hanya dapat dipahami dengan baik sesuai dengan bentuk-bentuknya yang berkaitan dengan waktu, kapan tindakan dalam kalimat tersebut terjadi, yang dalam bahasa Inggris disebut tenses. Tenses berhubungan dengan arti verba dari skala waktu. Tenses adalah kata berasal dari bahasa Latin, tempus yang berarti waktu yang dalam Bahasa Inggris adalah bentuk verba yang digunakan untuk mengindikasikan waktu atau menyelesaikan bentuk kegiatan pada saat pembicaraan. Jadi, tenses adalah metode yang digunakan dalam Bahasa Inggris yang menggambarkan waktu past atau present. Guru harus memulai dengan kalimat aktif terlebih dahulu untuk menjelaskan kalimat pasif kepada peserta didik. Kalimat dalam Bahasa Inggris terpengaruh oleh tenses, sedangkan kalimat dalam Bahasa Indonesia tidak mengenal tenses. Hal ini menjadi salah satu penyebab peserta didik mengalami kesulitan untuk memahami kalimat tersebut.

\section{Analisis Kontrastif}

Analisis kontrastif adalah suatu
kajian terhadap unsur-unsur kebahasaan. Menurut Lado (1975), analisis kontrastif adalah cara untuk mendeskripsikan kesulitan atau kemudahan pembelajar bahasa dalam belajar bahasa kedua dan bahasa asing. Analisis kontrastif bukan saja untuk membandingkan unsur-unsur kebahasaan dan sistem kebahasaan dalam bahasa pertama (B1) dengan bahasa kedua (B2), tetapi sekaligus untuk membandingkan dan mendeskripsikan latar belakang budaya dari kedua bahasa tersebut sehingga hasilnya dapat digunakan pengajaran bahasa kedua atau bahasa asing.

Pada dasarnya analisis kontrastif dapat dibedakan dalam beberapa bagian, secara gramatikal atau struktural, sintaksis dan pragmatis. Analisis gramatikal yaitu analisis yang berdasarkan pada tata bahasa dari masing-masing bahasa pertama dan kedua, analisis sintaksis adalah analisis yang berdasarkan pada asal kata atau bagaimana memaknai satu bahasa. Sedangkan analisis pragmatis adalah analisis yang berdasarkan pada penggunaan bahasa tersebut baik secara formal maupun informal. Guru dapat meramalkan kesalahan yang dibuat oleh peserta didik melalui analisis kontrastif antara bahasa yang dipelajari dan bahasa yang digunakan peserta didik sehari-hari, khususnya dalam komponen-komponen fonologi, morfologi, kosakata dan sintaksis. Berdasarkan hasil analisis kontrastif, guru dapat menyiapkan materi-materi yang sesuai dengan tingkat pemahaman peserta didik. James (1980) berpendapat bahwa analisis kontrastif ialah suatu aktivitas linguistik yang bertujuan untuk menghasilkan tipologi dua bahasa yang kontrastif, yang berdasarkan asumsi bahwa bahasa-bahasa itu dapat dibandingkan.

Menurut Halliday (1970) terdapat dua prinsip pada analisis kontrastif, yaitu memeriksa sebelum membandingkan dan membandingkan pola-pola tertentu dan bukan bahasa secara keseluruhan. Pada prinsip pertama kita tidak dapat membandingkan cara kerja sejumlah bahasa sebelum kita memeriksa cara kerja masing - masing bahasa itu. Jika 
kita ingin menggunakan bahasa ibu sebagai bahan perbandingan dalam mempelajari bahasa asing, kita tidak cukup hanya bisa berbahasa ibu tetapi kita juga harus menguasai bahasa yang akan kita bandingkan itu. Pada prinsip kedua, kita tidak dapat membandingkan Bahasa Indonesia dengan Bahasa Inggris secara keseluruhan. Yang dapat diperbandingkan adalah salah satu atau beberapa unsur atau pola yang terdapat pada masing-masing kalimat pasif dalam bahasa yang dibandingkan. Dan kita tidak dapat menarik kesimpulan dari kedua perbandingan ini karena setiap pola perbandingan dibahas secara terpisah.

Secara umum, dalam setiap perbandingan kita mengikuti tiga tahapan Analisis kontrastif berikut ini: (1) mendeskripsikan ciri-ciri yang akan diperbandingkan dari masing-masing bahasa, (2) memastikan bahwa ciri-ciri tersebut dapat dibandingkan, dan (3) membandingkan ciri-ciri dari kedua bahasa itu dengan melihat persamaan dan perbedaan di dalamnya. Jadi, analisis kontrastif adalah suatu kajian terhadap unsur-unsur kebahasaan untuk keperluan pengajaran bahasa kedua, terutama untuk mengatasi kesulitan dan kesalahan berbahasa yang dilakukan oleh peserta didik.

\section{Kalimat Pasif dalam Bahasa Inggris}

Kalimat aktif (active voice) adalah kalimat yang subjeknya melakukan sebuah pekerjaan atau kegiatan. Kebalikan dari kalimat ini adalah kalimat pasif (passive voice), yang memiliki arti $d i$-. Kalimat pasif merupakan salah satu bentuk kalimat dalam Bahasa Inggris. Dalam definisi singkat Passive Voice berarti suatu bentuk kata kerja transitif dimana secara tata Bahasa Inggris subjek dari kalimat berpelaku sebagai 'pasien', yaitu yang menerima aksi dari sebuah pekerjaan.
Kalimat Pasif umumnya kontras dengan Kalimat Aktif (Active Voice), kalimat ini bermakna suatu bentuk kata kerja transitif dimana subjek dari kalimat berpelaku sebagai 'agen', yaitu yang melakukan aksi dari sebuah pekerjaan. Dalam kalimat pasif, objek dari kalimat aktif menjadi subjek kalimat pasif. Kata kerja dalam kalimat pasif dalam bahasa Inggris selalu menggunakan to be dengan past participle (kata kerja bentuk ketiga: to do - did - done). Berikut ini adalah beberapa jenis kalimat pasif dalam bahasa Inggris:

1. Kalimat pasif yang pelakunya (doer, agent) tidak dikenal

Contoh:

Passive : An award was given to Mrs. Lee.

Active : Someone gave an award to Mrs. Lee.

2. Kalimat pasif yang pelakunya tidak jelas atau tidak penting

Contoh:

Passive : Rice is grown in many countries.

Active : People in many countires grow rice.

3. Kalimat pasif yang pelakunya diketahui atau diberi tekanan

Contoh:

Passive : Internet is being talked by a lot of people.

Active : A lot of people are talking about internet.

Kalimat aktif dan pasif dapat dibuat sebanyak tenses yang ada. Apabila kita mengubah kalimat aktif menjadi pasif atau sebaliknya, kita tidak boleh mengubah tenses-nya. Dengan kata lain, tenses kalimat aktif dan pasif harus sama. Perhatikan contoh berikut:

1. Simple Present:

Mary helps the boy.

The boy is helped by Mary.

2. Present Progressive:

Mary is helping the boy.

The boy is being helped by Mary. 
3. Present Perfect:

Mary has helped the boy.

The boy has been helped by Mary.

4. Simple Past:

Mary helped the boy.

The boy was helped by Mary.

5. Past Progressive:

Mary was helping the boy.

The boy was being helped by Mary.

6. Past Perfect:

Mary had helped the boy.

The boy had been helped by Mary.

7. Simple Future:

Mary will help the boy.

The boy will be helped by Mary.

8. Be going to:

Mary is going to help the boy.

The boy is going to be helped by Mary.

9. Future Perfect:

Mary will have helped the boy.

The boy will have been helped by Mary.

Bentuk kata kerja to be-verb-ed sebagai bentuk kalimat pasif tidak selalu menunjukkan suatu perbuatan, melainkan ada yang menunjukkan suatu keadaan. Contoh kalimat pasif yang menunjukkan perbuatan: "The door was opened by Tom". Contoh kalimat pasif yang menunjukkan keadaan: "My son is already bored with his new toy".

Rumus kalimat pasif adalah $\mathrm{S}+$ auxiliary verb + verb 3. Auxiliary verb ini dapat berupa to be (is, am, are, was, dan were), have, atau modal bergantung pada struktur kalimat aktif dan subjek kalimat pasif. Cara membuat kalimat pasif dari kalimat aktif, yaitu:

1. Gunakan is, am, atau are jika kalimat aktifnya menggunakan Verb 1. Jika kalimat aktifnya menggunakan verb 1 (simple present tense), gunakan is, am, are, atau is untuk membuat kalimat pasifnya.
Contoh:

Active We clean the house every week.

Passive The house is cleaned by us every week.

2. Gunakan was atau were jika kalimat aktifnya menggunakan verb 2 . Jika kalimat aktifnya menggunakan verb 2 (simple past tense), gunakan was atau were untuk membuat kalimat pasifnya.

Contoh:

Active I called my mother yesterday.

PassiveMy mother was called by me last night.

3. Sisipkan been di antara have dan verb 3. Jika kalimat aktif menggunakan have + verb 3 (perfect tense), sisipkan been di antara have dan verb 3 untuk membuat kalimat pasifnya. Namun, Anda harus menyesuaikan have dengan subjek di kalimat pasifnya.

Contoh untuk present perfect tense:

Active Sarah has made many cakes.

Passive Many cakes have been made by Sarah.

Contoh untuk past perfect tense:

Active Raffi had told a nice story to me.

Passive A nice story had been told by Raffi to me

4. Tambahkan being sebelum verb 3 jika kalimat aktifnya continuous tense. Jika kalimat aktifnya berupa continuous tense, tambahkan being sebelum verb 3 untuk membuat kalimat pasifnya. Penggunaan to be disesuaikan dengan subjek kalimat pasifnya.

Contoh untuk present continuous tense:

Active Agus is writing a book.

Passive A book is being written by Agus. 
Contoh untuk past continuous tense. Active We were discussing the problem last night.

Passsive The problem was being discussed by us last night.

5. Tambahkan be sebelum verb 3 jika kalimat aktif menggunakan modal. Jika kalimat aktif menggunakan modal, tambahkan be sebelum verb 3 untuk membuat kalimat pasifnya. Contoh:

Active I will solve the problem soon.

Passive The problem will be solved by me soon.

Ada beberapa hal yang perlu diperhatikan dalam membuat kalimat pasif, yaitu:

1. By dalam kalimat pasif tidak wajib ditulis (optional).

2. Kalimat non verbal (tanpa kata kerja) tidak dapat dibentuk menjadi kalimat pasif.

Contoh:

Active We are member of this cafe.

Passive This cafe is membered by us. (kalimat salah)

3. Kalimat tanpa objek tidak dapat dibentuk menjadi kalimat pasif.

Contoh:

I go to school every morning.

(school every morning adalah keterangan)

\section{Kalimat Pasif dalam Bahasa Indonesia}

Pengertian aktif dan pasif dalam kalimat menyangkut beberapa hal: (1) macam verba yang menjadi predikat, (2) subjek dan objek, dan (3) bentuk verba yang dipakai. Kalimat aktif adalah kalimat yang subjeknya melakukan suatu tindakan. Sedangkan kalimat pasif adalah kalimat yang subjeknya menderita (dikenai suatu tindakan) dari apa yang disebutkan dalam predikatnya. Ciri-ciri kalimat pasif: (1) Subjek pada kalimat aktif menjadi objek pada kalimat pasif, (2) Predikat menggunakan awalan di-, ke-an atau ter-, (3) Pada umumnya kata kerja didahului dengan kata ganti orang kudan kau-, dan (4) Kata "oleh" dalam kalimat pasif dapat dihilangkan dan tidak merubah makna. Penafsiran dalam bahasa Indonesia dilakukan dengan dua cara: (1) menggunakan verba berprefiks di- dan (2) menggunakan verba tanpa prefiks di-. Tidak semua kalimat aktif dapat dijadikan pasif. Kalimat aktif yang dapat diubah menjadi kalimat pasif adalah kalimat aktif yang memunyai objek. Kalimat perintah (command) dan kalimat seru (exclamation) juga tidak dapat dijadikan pasif. Pemasifan dalam bahasa Indonesia dilakukan dengan dua cara: (1) menggunakan verba berprefiks didan (2) menggunakan verba tanpa prefiks di-. Jika kita gunakan simbol $\mathrm{S}$ untuk subjek, $\mathrm{P}$ untuk predikat, dan $\mathrm{O}$ untuk objek, maka kaidah umum untuk pembentukan kalimat pasif dari kalimat aktif dalam bahasa Indonesia adalah sebagai berikut:

1. Cara pertama: pertukarkanlah $S$ dengan $O$. Kemudian gantilah prefiks meng- dengan $d i$ - pada $\mathrm{P}$. Lalu, tambahkan kata oleh di muka unsur yang tadinya $S$.

Contoh kalimat aktif:

a. Pak Toha mengangkat seorang asisten baru.

b. Ibu Gubernur akan membuka pameran itu.

c. Pak Saleh harus memperbaiki dengan segera rumah tua itu.

d. Kamu dan saya harus menyelesaikan tugas ini.

e. Saya sudah mencuci mobil itu.

Kalimat di atas dapat diubah menjadi kalimat pasif, sebagai berikut: kalimat (1) Seorang asisten baru diangkat Pak Toha. Kalimat (1) ini dapat juga dibuat: Seorang 
asisten baru diangkat oleh Pak Toha. Kalimat (2) Pameran itu akan dibuka oleh Ibu Gubernur. Keberterimaan kalimat (1) dalam bentuk yang pertama dan kedua menunjukkan bahwa kehadiran bentuk oleh pada kalimat pasif bersifat manasuka. Akan tetapi, jika verba predikat tidak diikuti langsung oleh pelengkap pelaku (yang sebelumnya subjek kalimat aktif), maka bentuk oleh wajib hadir. Atas dasar itulah maka bentuk kalimat (3) berikut kita terima: kalimat (3) Rumah tua itu harus diperbaiki dengan segera oleh Pak Saleh. Sedangkan bentuk tanpa kata oleh tidak bisa diterima sebagai bentuk kalimat pasif (Rumah tua itu harus diperbaiki segera Pak Saleh). Pemasifan dengan cara pertama umumnya digunakan jika subjek kalimat aktif berupa nomina atau frasa nominal seperti contoh kalimat (1)-(5) di atas, jika subjek kalimat pasif berupa pronomina persona, padanan pasifnya umumnya dibentuk dengan cara kedua. Akan tetapi, jika subjek kalimat aktif itu berupa gabungan pronomina dengan pronomina atau frasa lain, maka padanan pasifnya dibentuk dengan cara pertama. Karena itu, bentuk kalimat pasif kalimat (4) Tugas ini harus kamu dan saya selesaikan, yang dibentuk dengan cara kedua, kita tolak sebagai bentuk pasif kalimat (4) di atas. Kehadiran kata oleh pada kalimat (4) adalah wajib, jadi kalimat pasif yang berterima dari kalimat (4) adalah Tugas itu harus diselesaikan oleh kamu dan saya. Cara dua: padanan pasif dari kalimat aktif transitif yang subjeknya berupa pronomina dibentuk dengan cara kedua.
2. Cara kedua: pertama pindahkan $\mathrm{O}$ ke awal kalimat. Lalu, tanggalkan prefiks meng- pada P. Kemudian, pindahkan $\mathrm{S}$ ke tempat yang tepat sebelum verba. Cara dua ini bila diterapkan pada contoh kalimat (5), bentuk kalimat pasifnya adalah "Mobil itu sudah saya cuci". Jika subjek kalimat aktif transitif berupa pronomina persona ketiga atau nama diri yang relatif pendek, maka padanan pasifnya dapat dibentuk dengan cara pertama atau kedua seperti tampak pada contoh berikut:

a. Aktif: Mereka akan membersihkan ruangan ini.

Pasif 1: Ruangan ini akan dibersihkan (oleh) mereka.

Pasif 2 : Ruangan ini akan mereka bersihkan.

b. Aktif : Dia sudah membaca buku itu.

Pasif 1: Buku itu sudah dibaca olehnya/ (oleh) dia.

Pasif 2: Buku itu sudah dibacanya/ dia baca.

c. Aktif : Ayah belum mendengar berita duka itu.

Pasif 1 : Berita duka itu belum didengar (oleh) ayah.

Pasif 2: Berita duka itu belum ayah dengar.

Apabila subjek kalimat aktif transitif itu panjang, maka padanan kalimat pasifnya dibentuk dengan cara pertama. Jadi, bentuk seperti "Berita duka itu belum didengar oleh Susilowati Hamid" tidak dapat diubah menjadi "Berita duka itu belum Susilowati Hamid dengar". Pembentukan kalimat pasif dengan cara dua dari kalimat aktif transitif yang subjeknya berupa pronomina persona ketiga atau nama diri pada umumnya terbatas pada pemakaian sehari-hari. Pronomina aku, engkau, dan dia (yang mengikuti predikat) pada kalimat pasif cenderung 
dipendekkan menjadi ku-, kau-, dan -nya seperti pada contoh kalimat berikut:

a. Surat itu baru aku terima kemarin

b. Surat itu baru kuterima kemarin. Perubahan kalimat aktif transitif yang mengandung kata seperti ingin atau mau cenderung menimbulkan pergerseran makna. Contoh: "Andi ingin mencium Tuti". "Tuti ingin dicium Andi". Pada kalimat pertama adalah kalimat aktif, jelas bahwa yang ingin melakukan perbuatan mencium adalah Andi, tetapi pada kalimat kedua, orang cenderung menafsirkan bahwa yang menginginkan ciuman itu adalah Tuti bukan Andi. Tafsiran makna kalimat pasif yang berbeda dengan makna padanan kalimat aktif itu timbul karena kodrat kata ingin yang cenderung dikaitkan dengan unsur di sebelah kiri yang mendahuluinya. Hal ini tampak lebih nyata pada keganjilan pasangan kalimat "Andi ingin mencuci mobilnya" - "Mobilnya ingin dicuci Andi". Arti pasif dapat pula bergabung dengan unsur lain seperti unsur ketaksengajaan. Jika kalimat aktif diubah menjadi kalimat pasif dan dalam kalimat pasif itu terkandung pula pengertian bahwa perbuatan yang dinyatakan oleh verba itu mengandung unsur yang tak sengaja, maka bentuk prefiks yang dipakai untuk verba bukan lagi di-, melainkan ter-. Perhatikan perbedaan kalimat (1) dan kalimat (2) yang berikut ini:

1) a. Penumpang bus itu dilempar ke luar.

1) b. Penumpang bus itu terlempar ke luar.

2) a. Dia dipukul kakaknya.

2) b. Dia terpukul kakaknya
Kalimat (1a dan 2a) menunjukkan bahwa seseorang melakukan perbuatan itu dengan niat dan kesengajaan. Sebaliknya, kalimat (1b dan 2b) mengacu ke suatu keadaan atau ke ketidaksengajaan si pelaku perbuatan. Pada kalimat (1b) mungkin saja penumpang tadi terlempar oleh orang lain, atau mungkin juga oleh guncangan bus yang terlalu besar. Di samping makna ketaksengajaan itu, verba pasif yang memakai ter- juga dapat menunjukkan kekodratan. Artinya, kita tidak memasalahkan siapa yang melakukan perbuatan tersebut sehingga seolah-olah sudah menjadi kodratlah bahwa sesuatu harus demikian keadaannya. Perhatikan contoh kalimat berikut:

1) Gunung Merapi terletak di Pulau Jawa.

2) Soal ini terlepas dari rasa senang dan tidak senang.

Pada contoh (1) dan (2) tidak ada unsur sengaja atau tidak sengaja, dan kita pun tidak memasalahkan siapa yang meletakkan gunung itu atau yang melepaskan soal ini. Bentuk kalimat pasif lain yang bermakna adversatif tampak pada contoh berikut:

1) a. Soal itu diketahui oleh orang tuanya.

b. Soal itu ketahuan oleh orang tuanya.

2) a. Partai kita dimasuki unsur kiri.

b. Partai kita kemasukkan unsur kiri.

Di sini perlu ditekankan bahwa makna kalimat yang predikatnya memakai ke-an ini adalah pasif dengan tambahan makna adversatif, yakni makna yang tidak menyenangkan. 
Perbandingan Kalimat Pasif dalam Bahasa Inggris dan Bahasa Indonesia

Kalimat pasif dalam Bahasa Inggris hanya mengenal "to be + past participle" yang tergantung pada waktu kejadiannya (sesuai tenses). Konteks kalimat harus diperhatikan sehingga makna yang terkandung di dalamnya benar-benar dapat dimengerti. Sementara dalam Bahasa Indonesia jika dilihat dari strukturnya menggunakan di-, ter- ataupun ke-. Setelah dianalisis dan dicari padanan dan perbandingannya, penulis menemukan persamaan dan perbedaan kalimat pasif dalam Bahasa Inggris dan Bahasa Indonesia yang dapat dilihat secara struktural maupun secara pragmatis.

Dalam Bahasa Inggris, kata kerja dalam kalimat pasif mempunyai beragam bentuk sesuai dengan "tenses". Secara umum, rumus bentuk tersebut bisa disimpulkan sebagai - kata kerja bantu (auxiliary verb) be + past participle. Ketentuan penggunaan be pada kalimat pasif tergantung pada bentuk waktu (tense) dari kalimat aktifnya dan tergantung pula pada subjek kalimat, apakah subjek tersebut tunggal (singular) atau jamak (plural). Kata kerja utama (main verb) dalam kalimat pasif harus berbentuk past participle. Untuk kata kerja beraturan (regular verb) dalam Bahasa Inggris, bentuk past participle-nya diakhiri dengan -ed, seperti: surprise surprised, mail - mailed. Sedangkan sebagian kata kerja dalam Bahasa Inggris ada yang tidak beraturan (irregular verb), seperti, teach - taught, drive - driven. Pada kalimat pasif, kata kerja yang digunakan adalah kata kerja transitif (transitive verbs). Kata kerja transitif merupakan kata kerja yang diikuti oleh objek. Hanya kata kerja transitif yang bisa digunakan dalam pembentukan kalimat pasif, sedangkan kata kerja intransitif (intransitive verbs) tidak bisa digunakan dalam pembentukan kalimat pasif. Salah satu contoh kata kerja intransitif dalam Bahasa Inggris adalah happen, apabila ada kalimat aktif dalam Bahasa Inggris yang terdapat kata kerja happen, maka kalimat tersebut tidak mungkin diubah ke dalam kalimat pasif. "An accident happened" tidak bisa dipasifkan menjadi "An accident was happened" (bentuk kalimat yang salah). Dalam kalimat pasif, pelakunya diungkapkan dengan frasa "oleh...". Namun frasa tersebut boleh dihilangkan karena sudah jelas siapa pelaku kata kerja tersebut. Kalimat pasif dalam Bahasa Indonesia dilihat dari strukturnya menggunakan di-, ter- ataupun ke-, yang dalam Bahasa Inggris hanya mengenal to be + past participle yang tergantung waktu kejadian (sesuai tenses).

Kata kerja pasif Bahasa Inggris diterjemahkan ke dalam Bahasa Indonesia dengan menggunakan awalan di- atau ter- di depan kata kerja. Awalan ter- mempunyai makna konotasi bahwa perbuatan tersebut tidak disengaja. Contohnya: "That old man was struck by a car"; terjemahannya: "Orang tua itu tertabrak mobil". Dalam kalimat itu, biasanya mobil tidak dengan sengaja menabrak orang tua. Hal itu terjadi karena ketidaksengajaan. Ada kalanya penerjemahan ke dalam Bahasa Indonesia tidak dalam kalimat pasif, hal inilah yang membuat peserta didik kesulitan dalam membedakan mana yang harus diartikan di-, ter- atau tidak keduanya. Oleh karena itu, peserta didik perlu mengetahui maksud dan tujuan kalimat tersebut digunakan dan kapan digunakan.

\section{SIMPULAN}

Analisis padanan dan perbandingan kalimat pasif dalam Bahasa Inggris dan Bahasa Indonesia 
dapat dilihat secara struktural maupun secara pragmatis. Secara struktural terdapat persamaan kalimat pasif dalam Bahasa Inggris dan Bahasa Indonesia yaitu subyeknya yang dikenai tindakan dan obyeknya sebagai pelaku yang ditandai dengan kata by atau kata oleh dalam Bahasa Indonesia. Sedangkan perbedaannya adalah dalam Bahasa Inggris terdapat perbedaan waktu pengucapan. Dalam Bahasa Indonesia, kalimat pasif diucapkan sama meskipun diucapkan sekarang (present), masa depan (future), ataupun masa lalu (past). Dalam Bahasa Inggris, kata kerja yang digunakan dalam masing-masing tenses berbeda karena perbedaan waktu, sedangkan dalam Bahasa Indonesia tidak ada perbedaan penggunaan kata kerja.

Secara pragmatis, makna yang terkandung di dalam kalimat pasif Bahasa Inggris sama dengan makna yang terkandung dalam Bahasa Indonesia, yaitu sama-sama menyatakan obyek sebagai pelaku dan subyek sebagai penerima tindakan (yang dikenai tindakan). Perbedaannya terletak pada makna adversatif dan ketidaksengajaan. Dalam Bahasa Inggris tidak terdapat kalimat pasif yang bermakna ketidaksengajaan.

\section{DAFTAR PUSTAKA}

Akmajian, A. and Heny F. W. (1975). An Introduction to the Principles of

Transformational Syntax. The Massachusetts Institute of Technology Press.

Alwi, H. dkk. (2010). Tata Bahasa Baku Bahasa Indonesia. Penerbit Balai Pustaka.
Azar, B. S. (2002). Understanding and Using English Grammar (Third Edition). Longman.

Brown, H. D. (2004). Principles of Language Learning and Teaching. San Francisco: Prentice Hall Regents.

Halliday, M.A.K. (1970). The Linguistic Sciences and Language Teaching. Bloomington: Indiana University Press.

Indihadi, D. Analisis Kontrastif Suatu Kajian Unsur Kebahasaan. http://file.upi.edu/direktori/dual modes/pembinaan_bahasa_Indo nesia_kedua/9_bbm_7.pdf. Di akses 22 Mei 2017.

Irianto, A. (2011). Kekerasan dalam Serial Televisi (Studi Analisis Isi Tentang Adegan Kekerasan dalam Serial Televisi Animasi Jepang Naruto Shippunden yang Ditayangkan di Global Tv Periode Bulan November 2010), (Skripsi). Surakarta: FKI UMS (tidak dipublikasikan).

James, C. (1980). Contrastive Analysis. England: Longman.

Lado, R. (1975). Linguistics across Cultures. Ann Arbor: The University of Michigan Press.

Miles, M. B dan A Michael Huberman. (2007). Analisis Data Kualitatif Buku Sumber tentang MetodeMetode Baru. Jakarta: Universitas Indonesia Press.

Richards, J. C. (1974). Error Analysis: Perspectives on Second Language Acquisition. London: Longman Group Limited. 